\title{
The Volumetrical, Geometrical and Frictional Properties of White Mulberry (Morus alba L.) Fruits
}

\author{
Ebubekir Altuntas*
}

Department of Biosystems Engineering, Faculty of Agriculture, University of Gaziosmanpasa, 60240 Tasliciftlik/Tokat, Turkey

\section{A R T I C L E I N F O}

\section{Article history:}

Received 01 August 2016

Accepted 05 October 2016

Available online, ISSN: 2148-127X

Keywords:

White mulberry

Surface area

Angle of repose

Static coefficient of friction

Porosity

${ }^{*}$ Corresponding Author:

E-mail: : ebubekir.altuntas@gop.edu.tr \begin{abstract}
A B S T R A C T
The volumetrical, geometrical and frictional properties of white mulberry fruits (Morus alba L.) determined at a moisture content of $13.89 \%$ (d.b.). The mean values of the fruit mass, porosity, fruit volume, fruit and bulk densities values of white mulberry fruits were found as $1.06 \mathrm{~g}, 75.3 \%, 0.53 \mathrm{~cm}^{3}, 1911.7 \mathrm{~kg} / \mathrm{m}^{3}$ and $454.0 \mathrm{~kg} / \mathrm{m}^{3}$, respectively. The mean values of the surface area, sphericity and geometric mean diameter and were $4.16 \mathrm{~cm}^{2}$, $71.02 \%$ and $11.5 \mathrm{~mm}$, respectively. The angle of repose of the white mulberry fruits was found as $22.1^{\circ}$ and also, the mean values of dynamic and static coefficient of friction against plywood, chipboard, galvanized steel, rubber and mild steel surfaces were determined and the highest dynamic and static coefficients of friction values of white mulberry fruits were found for rubber surface.
\end{abstract}

\section{Introduction}

There are about 68 species in the genus Morus, and the majority of them occur in Asia. In China, there are over a thousand varieties under cultivation. They originated from four main species, the white mulberry (Morus alba L.), the Lu mulberry (Morus multicaulis), the Mountain mulberry (Morus bombycis) and the Guangdong Mulberry (Morus atropurpurea). The most popular species in the world are believed to be Morus alba and Morus indica (Sánchez, 2016). Morus alba L.and Morus nigra L. (both known as mulberry) are deciduous trees belonging to the family Moraceae. (Zelová et al., 2014). Mulberry kinds are classified as white mulberry (Morus alba L.), black mulberry (Morus nigra L.), and red mulberry (Morus rubra L.). They extensively are used for fruits and their leaves. Mulberry fruits are effectively used in folk medicines to treat fever, protect liver from damage, strengthen the joints, and facilitate discharge of urine and lower blood pressure. Mulberry fruit contains essential fatty acids that humans cannot synthesis, and must be obtained through diet. These essential fatty acids are necessary for the formation of healthy body (Hazbavi, 2014). Mulberry plants have edible and tasty fruits, In most European countries, mulberries are grown for fruit production rather than foliage (Sánchez-Salcedo et al., 2016). White mulberry has high moisture content at harvest. Because of the short harvesting season and their sensitivity to storage, fresh mulberry fruits should be preserved in some form (Darvishi, et al. 2014).
White mulberry originated in Western Asia, red mulberry in North and South America, and black mulberry is from Southern Russia. The production of mulberry in 2000 was $68,000 \mathrm{t}$ in Turkey. The fruits of white mulberries are often harvested by spreading a sheet on the ground and shaking the limbs. In addition, mulberry is used in mulberry pekmez, juices, paste, marmalade and wine production in Turkey (Doymaz, 2004). Ethno-botanical usage of mulberry fruits include preparation of jams, ice-creams, vinegars, juices, wine and other food and cosmetic products (Natic et al., 2014).

White mulberry can grow in various climates and soils.Also, White mulberry is a naturally growing fruit tree in our contry. It can withstand even to arid, lessproductive, cold climates and salty water conditions. Fungi and insects and its yellow wood, it is used in furniture and musical instruments making. It is also used as an ornamental tree (Gündüz, et al., 2009). The mulberry seed oil, very rich in linoleic acid, may be a healthy valuable and dietary fat. Mulberry seed oil is rather poor in linolenic acid and the low levels of linolenic acid are desired in edible oils, because high levels of this fatty acid can cause unfavourable odor and taste (Baydar and Akkurt, 2001).

Mulberry fruits are consumed as fresh, dried, or processed food products in Turkey. 'Pestil' is made from white mulberry are special traditional foods of Turkey. Pestil and köme in Turkey are produced from fruit juice such as mulberry, grape, apple, rose hip, fig, or cornelian cherry and also from concentrated fruit juice. In 
traditional medicine, the fruit is used to treat prematurely grey hair, treat fever, headache, red dry and sore eyes, to "tonify" the blood, and treat constipation and diabetes. White mulberry leaves extract help restore the vascular reactivity of diabetic rats. Free radical-induced vascular dysfunction plays a key role in the pathogenesis of vascular disease found in chronic diabetic patients (Y1ldiz, 2013).

The physical (volumetrical, geometrical and frictional) properties of white mulberry fruits are to be known for harvesting, storing, handling, granding and processing in design and improve of relevant machines. The porosity, bulk density and angle of repose of white mulberry fruits affect the structural loads at silo design, and they are important in designing of storage and transporting structures. The coefficient of friction of the white mulberry fruits against the various surfaces is also necessary in designing of the storing, transporting and conveying structures.

In recent years, the volumetrical, geometrical and frictional properties for the different agricultural materials have been studied such as fresh palm, date fruit, medlar, service tree, and juniper berries by Owolarafe et al. (2007), Jahromi et al. (2008), Altuntas et al. (2013), Altuntas et al. (2015), Altuntas, (2015). However, studies conducted on the volumetrical, geometrical and frictional properties of white mulberry fruits have not been adequately studied. The objective of this study was to investigate the physical (volumetrical, geometrical and frictional) properties for white mulberry fruits such as sphericity, size dimension, mass, geometric mean diameter, porosity, bulk density, fruit density, volume, the dynamic and static coefficients of friction on the different surfaces and angle of repose.

\section{Materials and Methods}

Dried white mulberry fruits (Morus alba L.) used for experiments were obtained from a special market in Tokat, Turkey. The white mulberry fruit samples were manually cleaned to remove dust, dirt, broken and immature fruits, and all foreign matter. The moisture content of the white mulberry fruit samples was determined by oven drying at $105 \pm 1^{\circ} \mathrm{C}$ for $24 \mathrm{~h}$. Each of the white mulberry fruit samples was replicated three times and the mean moisture content of white mulberry fruits was found as $13.89 \%$ d.b. (Altuntas et al. 2015).

The volumetrical characteristics of white mulberry fruits such as mass, volume fruit and bulk densities, and porosity were determined. The fruit mass was measured using an electronic balance with $0.001 \mathrm{~g}$ accuracy. The fruit density and volume of white mulberry fruits were determined using the liquid displacement method. Toluen $\left(\mathrm{C}_{7} \mathrm{H}_{8}\right)$ was used rather than water because it is absorbed by white mulberry fruit samples to a lesser extent (Mohsenin, 1986). The bulk density was determined with a weight per hectolitre tester which was calibrated in $\mathrm{kg} / \mathrm{m}^{3}$ (Celik and Ercisli, 2009). The porosity (P) of white mulberry fruits was determined to the method presented by Mohsenin (1986). To determine of geometrical properties of the white mulberry fruits, one hundred sample fruits were randomly selected and length, width and thickness were measured using a dial-micrometer to an accuracy of $0.01 \mathrm{~mm}$. The sphericity $(\Phi)$ and the geometric mean diameter $\left(D_{g}\right)$, and surface area $(S)$ of white mulberry fruits were determined methods presented by Mohsenin (1986). The frictional properties of white mulberry fruits such as dynamic and static coefficient of friction were determined.

To determine the angle of repose of white mulberry fruits, bottomless and topless cylinder with $500 \mathrm{~mm}$ height and $300 \mathrm{~mm}$ diameter was used. The cylinder was placed at the center of a raised circular plate and was filled with white mulberry fruits and the cylinder was raised slowly until it formed a cone on a circular plate. The angle of repose $(\theta)$ of white mulberry fruit samples was calculated from the measurement of the height of the cone and the diameter of cone (Altuntas and Demirtola, 2007).

The dynamic and static coefficient of friction of white mulberry fruits fruits were measured by a friction device. The experiment was conducted on white mulberry fruits using friction surfaces such as rubber, galvanized metal, plywood, mild steel and chipboard. The friction measuring device is formed by a friction surface, an electronic unit, and a metal box. The electronic unit covers electronic variator, the mechanical force unit, PC, electronic ADC card and loadcell (Altuntas and Demirtola, 2007). The force of friction was measured by the loadcell, and converted by the ADC card, and data were recorded in a computer. The maximum value of friction force was obtained when box started moving, and this was used to calculate the static coefficients of friction of white mulberry fruits. The average value of coefficient of friction was used to calculate the dynamic coefficients of friction. For each experiment, the sample box was emptied and refilled with a different sample at the same moisture content (Altuntas, 2015).

\section{Results and Discussion}

The values of physical properties such as volumetrical and geometrical properties of white mulberry fruits were given in Table 1. The fruit mass varied from 0.57 to 1.57 $\mathrm{g}$ for white mulberry fruits and the fruit volume of white mulberry changed from 0.09 to $0.86 \mathrm{~cm}^{3}$. The porosity, the fruit density and bulk density for white mulberry fruits were changed from 73.1 to $79.6 \%, 1689.2$ to 2222.2 $\mathrm{kg} / \mathrm{m}^{3}$ and 432.2 to $488.8 \mathrm{~kg} / \mathrm{m}^{3}$, respectively. The values of geometrical properties of white mulberry fruits were given in Table 1. The length, width and thickness of white mulberry fruits ranged from 17.6 to $20.6 \mathrm{~mm}, 7.4$ to 11.6 $\mathrm{mm}, 7.1$ to $12.6 \mathrm{~mm}$, respectively. The sphericity, geometric mean diameter and surface area values of white mulberry fruits were found from 57.3 to $88.6 \%$ and 9.2 to $13.1 \mathrm{~mm}$, and 2.6 to $5.4 \mathrm{~cm}^{2}$, respectively.

The bulk and fruit densities and porosity of wild medlar were reported as $379.9 \mathrm{~kg} / \mathrm{m}^{3}, 1031.1 \mathrm{~kg} / \mathrm{m}^{3}$, and $63.1 \%$ by Haciseferogullari et al. (2005), respectively. The bulk and fruit densities and porosity of white 
mulberry fruits were found lower than wild medlar (Haciseferogulları et al. (2005). The fruit and bulk densities of white mulberry fruits were found lower than Japan flowering crabapple fruits; while, the porosity of white mulberry fruits was found higher than Japan flowering crabapple fruits (Altuntas and Karaosman, 2015). The fruit mass, volume, the fruit and bulk density densities of white mulberry fruits were found higher than juniper berry fruits (Altuntas, 2015).

The relationship between length, width, thickness, sphericity, geometric mean diameter and surface area of white mulberry fruit and the correlation coefficients (r) for these relations were determined as follows:

$$
L=1.67 W=1.72 T=1.42 D_{g}=3.95 S
$$

The relations between $L / D_{g}, L / S, L / \Phi$ have been found to be statistically significant, whereas, $L / W$ and $L / T$ has not been found to be statistically significant (Table 2).The statistics related with dimensional properties of white mulberry fruit were found to be meaningful. Partly similar results were found for apricot pit and kernel (Gezer et al., 2002); wild medlar ((Haciseferogullari et al., 2005); apricot cultivars (Haciseferogullari et al., 2007), wild plum fruits and apple (Altuntas et al., 2012), respectively.

Haciseferogullari et al (2005) reported that the fruit mass, fruit volume, sphericity and the geometric mean diameter of wild medlar was reported as $12.0 \mathrm{~g}, 13.7 \mathrm{~cm}^{3}$, 0.90 and $28.9 \mathrm{~mm}$ at $72.2 \%$ d.b. moisture content. The size dimension such as fruit length, width and thickness were reported as $30.25 \mathrm{~mm}$ and $19.94 \mathrm{~mm}$ and $15.66 \mathrm{~mm}$ for the fresh palm by Owolarafe et al. (2007), respectively. The sphericity of white mulberry fruits are lower than reported for medlar (Haciseferogullari et al., 2005; Altuntas et al., 2013). The mean goemetric mean diameter, surface area, the fruit volume, and the sphericity of Japan flowering crabapple were reported as $34.0 \mathrm{~mm}$, $36.5 \mathrm{~mm}^{2}, 21.1 \mathrm{~mm}^{3}$, and $97.7 \%$, by Altuntas and Karaosman (2015), respectively. The sphericity of white mulberry fruits were found lower than Juniper berry fruits; while, the geometric mean diameter of white mulberry fruits was found higher than Juniper berry fruits (Altuntas, 2015).

The angle of repose for white mulberry fruits changed from 20.21 to $26.41^{\circ}$. Aydin et al (2002) reported that the mean angle of repose of mahaleb were changed 25 to $30.5^{\circ}$. The angle of repose of white mulberry fruits was lower than mahaleb (Aydin et al., 2002).

The values of static and dynamic coefficients of friction against the various test surfaces for chipboard, galvanized metal, rubber, mild steel and plywood for white mulberry fruits were presented in Table 3 . The dynamic coefficients of friction mean values against rubber, mild steel chipboard, galvanized steel and plywood surfaces for white mulberry fruits were 0.86 , $0.59,0.59,0.67$ and 0.57 , respectively. The static coefficients of friction mean values of white mulberry fruits against galvanized steel, rubber, mild steel, plywood and chipboard surfaces were $0.76,0.99,0.77,0.88$ and 0.76 , respectively. From these results, dynamic coefficient of friction of white mulberry fruits is lower than static coefficients of friction. Demir and Kalyoncu (2003) reported that the static coefficient of friction were ranged from 0.79 to $0.85 ; 0.89$ to $0.91 ; 0.93$ to 0.96 for steel, plywood and rubber friction surfaces for cornelian cherry, respectively. The static and dynamic coefficient of frictions was higher for white mulberry fruits againts rubber surface than the other friction surfaces. Similar results were found for cornelian cherry fruits and Juniper berry fruits by Demir and Kalyoncu (2003); Altuntas (2015).

Table 1 Volumetrical and geometrical properties of white mulberry fruits

\begin{tabular}{|c|c|c|c|c|}
\hline Volumetrical properties & Mean & Maximum & Minimum & $\mathrm{SD} *$ \\
\hline Fruit mass, M (g) & 1.055 & 1.569 & 0.569 & 0.200 \\
\hline Fruit volume, $\mathrm{V}\left(\mathrm{cm}^{3}\right)$ & 0.525 & 0.860 & 0.090 & 0.094 \\
\hline Porosity, P (\%) & 75.30 & 79.57 & 73.13 & 3.701 \\
\hline Bulk density, $\rho_{b}\left(\mathrm{~kg} / \mathrm{m}^{3}\right)$ & 453.96 & 488.76 & 432.15 & 18.87 \\
\hline Fruit density, $\rho_{\mathrm{t}}\left(\mathrm{kg} / \mathrm{m}^{3}\right)$ & 1911.70 & 2222.20 & 1689.20 & 227.20 \\
\hline \multicolumn{5}{|l|}{ Geometrical properties } \\
\hline Length, L (mm) & 16.33 & 20.55 & 17.57 & 2.06 \\
\hline Width, W (mm) & 9.84 & 11.60 & 7.37 & 0.82 \\
\hline Thickness, $\mathrm{T}(\mathrm{mm})$ & 9.58 & 12.59 & 7.13 & 0.84 \\
\hline Sphericity, $\Phi(\%)$ & 71.02 & 88.64 & 57.26 & 0.06 \\
\hline Geometric mean diameter, $\mathrm{D}_{\mathrm{g}}(\mathrm{mm})$ & 11.48 & 13.09 & 9.15 & 0.75 \\
\hline Surface area, $\mathrm{S}\left(\mathrm{cm}^{2}\right)$ & 4.16 & 5.38 & 2.63 & 0.54 \\
\hline
\end{tabular}

*SD: Standard deviation.

Table 2 The correlation coefficient of white mulberry fruits at $13.89 \%$ moisture content (d.b.)

\begin{tabular}{l|ccc}
\hline \multicolumn{1}{c|}{ Particulars } & Ratio & Degress of freedom & Correlation coefficient (R) \\
\hline $\mathrm{L} / \mathrm{W}$ & 1.669 & 98 & $0.1308^{\mathrm{ns}}$ \\
$\mathrm{L} / \mathrm{T}$ & 1.717 & 98 & $0.0378^{\mathrm{ns}}$ \\
$\mathrm{L} / \mathrm{D}_{\mathrm{g}}$ & 1.420 & 98 & $0.7102 * *$ \\
$\mathrm{~L} / \Phi$ & 0.234 & 98 & $-0.8587 * *$ \\
$\mathrm{~L} / \mathrm{S}$ & 3.947 & 98 & $0.7121 * *$ \\
\hline
\end{tabular}

${ }^{\mathrm{ns}}$ non significant, ${ }^{* *}$ Significant at $1 \%$ level. 
Table 3 The coefficient of friction (dynamic and static) values for white mulberry fruits

\begin{tabular}{l|cc}
\hline \multicolumn{1}{c}{ Friction surfaces } & \multicolumn{2}{c}{ Coefficient of friction } \\
\cline { 2 - 3 } & Dynamic & Static \\
\hline Mild steel & $0.593 \pm 0.016$ & $0.769 \pm 0.037$ \\
Chipboard & $0.587 \pm 0.004$ & $0.757 \pm 0.016$ \\
Rubber & $0.861 \pm 0.047$ & $0.992 \pm 0.059$ \\
Galvanized metal & $0.674 \pm 0.016$ & $0.773 \pm 0.047$ \\
\hline Plywood & $0.570 \pm 0.009$ & $0.879 \pm 0.035$ \\
\hline
\end{tabular}

$\pm:$ Standard deviation.

\section{Conclusions}

The volumetrical, geometrical and frictional properties for white mulberry fruits measured will serve to improve of relevant machines and facilities for harvesting, storing, food handling, granding and processing. The following conclusions are drawn from the investigation on the volumetrical, geometrical and frictional properties of white mulberry fruits:

The bulk and fruit densities were varied from and 255.2 to $273.0 \mathrm{~kg} / \mathrm{m}^{3}$ and 911.9 to $972.9 \mathrm{~kg} / \mathrm{m}^{3}$, respectively. The surface area, the geometric mean diameter and sphericity were found as $5.5 \mathrm{~cm}^{2}, 13.0 \mathrm{~mm}$, and 0.71 , respectively. The relations between $L / \Phi$ has not been found to be statistically significant, whereas, $L / D_{g}$, $L / T, L / S$ and $L / W$ have been found to be statistically significant. The angle of repose of white mulberry fruits varied from 20.2 to $26.4^{\circ}$. The dynamic and static and coefficients of friction of white mulberry fruits among on the different friction surfaces were greater at rubber surface compared to the mild steel, plywood, chipboard and galvanized metal friction surfaces.

\section{References}

Altuntas E, Demirtola H. 2007. Effect of moisture content on physical properties of some grain legume seeds. New Zealand Journal of Crop and Horticultural Science, 35: 423-433.

Altuntas E, Ozturk B, Ozkan Y, Yildiz K. 2012. Physicomechanical Properties and Colour Characteristics of Apple as Affected by Methyl Jasmonate Treatments. International Journal of Food Engineering. Volume 8, Issue 1, DOI: 10.1515/1556-3758.2388, May 2012.

Altuntas E, Gul EN, Bayram M. 2013. The physical, chemical and mechanical properties of medlar (Mespilus germanica L.) during physiological maturity and ripening period. Journal of Agricultural Faculty of Gaziosmanpasa University (JAFAG), 30 (1): 33-40.

Altuntas E, Karaosman N. 2015. The post-harvest engineering properties of Japan flowering crabapple (Malus floribunda) fruits. Agricultural Engineering International: The CIGR EJournal. Manuscript, 17(1): 264-272, 2015.

Altuntas E, Yildiz M, Gul EN. 2015. The effect of ripening periods on physical, chemical and mechanical properties of service tree (Sorbus Domestica L.) fruits. Agricultural Engineering International: The CIGR EJournal. Manuscript, 17(2): 259-266, 2015.

Altuntas E. 2015. The geometric, volumetric and frictional properties of Juniper berries. American Journal of Food Science and Nutrition Research, 2015; 2(1): 1-4.

Aydin C, Öğüt H, Konak M. 2002. Some physical properties of Turkish Mahaleb. Biosystem Engineering, 82(2): 231-234.
Baydar NG, Akkurt M. 2001. Oil content and oil quality properties of some grape seeds. Turkish Journal of Agriculture Forestry, 25: $163-168$

Celik A, Ercisli S. 2009. Some physical properties of pomegranate cv. Eksinar. Int. Agrophysics, 23: 295-298.

Darvishi H, Zarein M, Minaei S, Khafajeh H. 2014. Exergy and Energy Analysis, Drying Kinetics and Mathematical Modeling of White Mulberry Drying Process. International Journal of Food Engineering 2014; 10(2): 269-280.

Demir F, Kalyoncu IH. 2003. Some nutritional, pomological and physical properties of cornelian cherry (Cornus mas L). Journal of Food Engineering, 60: 335-341.

Doymaz I. 2004. Drying kinetics of white mulberry. Journal of Food Engineering, 61: 341-346.

Gündüz G, Yıldırım N, Şirin G, Onat SM. 2009. Some Anatomical, Chemical, Physical And Mechanic Properties of White Mulberry (Morus alba L.) Tree. Journal of Forestry, 5(1): 132149. (In Turkish).

Gezer İ, Haciseferoğulları H, Demir F. 2002. Some physical properties of Hacıhaliloğlu apricot pit and its kernel_ Journal of Food Engineering, 56: 49-57.

Haciseferogulları H, Ozcan M, Sonmete MH, Ozbek O. 2005. Some physical and chemical parameters of wild medlar (Mespilus germanica L.) fruit grown in Turkey. Journal of Food Engineering, 69: 1-7.

Hacıseferoğulları H, Gezer İ, Özcan MM, Murat Asma B. 2007. Post harvest chemical and physical-mechanical properties of some apricot varieties cultivated in Turkey. Journal of Food Engineering 79: 364-373.

Hazbav I. 2014. Estimation of maximum height for bulk of white mulberry. International Journal of Biosciences. Vol.4 (1): 205211.

Jahromi MK, Rafiee S, Jafari A, GhasemiBousejin MR, Mirasheh R, Mohtasebi SS. 2008. Some physical properties of date fruit (cv. Dairi). International Agrophysics, 22(3): 221-224.

Mohsenin NN. 1986. Physical Properties of Plant and Animal Materials. Gordon and Breach Press, New York, USA.

Natic' MM, Dabic' DC², Papetti A, Fotiric'-Akšic' MM, Ognjanov V, Ljubojevic' M, 2014. Analysis and characterisation of phytochemicals in mulberry (Morus alba L.) fruits grown in Vojvodina, North Serbia. Food Chemistry, 171: 128-136.

Owolarafe OK, Olabige MT, Faborode MO. 2007. Physical and mechanical properties of two varieties of fresh oil palm fruit. Journal of Food Engineering, 78: 1228-1232.

Sánchez M. 2016. FAO Electronic Conference on Mulberry For Anımal Production (Morus1-L). World Distribution and Utilization of Mulberry, Potential for Animal Feeding. http://www.fao.org/ag/AGa/AGAP/FRG/Mulberry/Papers/PDF/ Intro.pdf (Access to web: 20 September 2016).

Y1ldiz O. 2013. Physicochemical and sensory properties of mulberry products: Gümüşhane pestil and köme. Turk J Agric For. 37, 762-771.

Zelová H, Hanáková Z, C`ermáková Z, Šmejkal K, Dall e`Acqua S, Babula P, Cvačka J, andHošek J. 2014. Evaluation of antiinflammatory activity of prenylated substances isolated from Morus alba and Morus nigra. Journal of Natural Products, 77, 1297-1303. 